\title{
Globe
}

Revue internationale d'études québécoises

\section{Micheline Cambron [éd.] : Le Journal Le Canadien. Littérature, espace public et utopie, 1836-1845. Montréal, Fides, coll. « Nouvelles études québécoises ", 1999, 419 p.}

\section{Lucie Robert}

Volume 3, numéro 1, 2000

URI : https://id.erudit.org/iderudit/1000572ar

DOI : https://doi.org/10.7202/1000572ar

Aller au sommaire du numéro

Éditeur(s)

Globe, Revue internationale d'études québécoises

ISSN

1481-5869 (imprimé)

1923-8231 (numérique)

Découvrir la revue

Citer ce compte rendu

Robert, L. (2000). Compte rendu de [Micheline Cambron [éd.] : Le Journal Le Canadien. Littérature, espace public et utopie, 1836-1845. Montréal, Fides, coll. " Nouvelles études québécoises ", 1999, 419 p.] Globe, 3(1), 163-165.

https://doi.org/10.7202/1000572ar d'utilisation que vous pouvez consulter en ligne.

https://apropos.erudit.org/fr/usagers/politique-dutilisation/ 
relancer la recherche dans de nouvelles directions, n'est-ce pas là le propre des contributions stimulantes?

Michel Lacroix

Université McGill

Micheline Cambron [éd.]

Le Journal Le Canadien.

Littérature, espace public et utopie, 1836-1845.

Montréal, Fides, coll. «Nouvelles études québécoises», 1999,419 p.

Pendant huit années, Micheline Cambron a réuni autour d'elle une équipe d'étudiants pour dépouiller les journaux de la première moitié du XIXe siècle. Le Journal Le Canadien. Littérature, espace public et utopie, 1836-1845 livre les résultats de ce projet à propos du Canadien, journal habituellement considéré comme le principal lieu du discours national dans les années qui entourent les rébellions et l'adoption de l'Acte d'Union. L'hypothèse générale qui sous-tend ce travail est empruntée à Fernand Dumont qui, dans Genèse de la société québécoise, écrivait que «la présence de l'utopie constitue un trait marquant du discours culturel québécois à partir du mitan du XIXe siècle». À cette époque où se forme l'espace public et où apparaît l'idée d'une littérature nationale, la conscience serait caractérisée par une sorte de malaise existentiel qui se convertit en dystopie. Le discours opère alors l'exercice de ce que Dumont nommait encore les "possibles latéraux" par où émerge l'utopie. Conçu comme un objet inséré entre la conscience individuelle et le monde, le journal devient ainsi générateur d'un autre monde. Dans les années étudiées, Le Canadien n'offre guère de récit utopique homogène, mais il présente ce que les auteurs nomment un «ethos utopiquen, propre à apparaître à la surface des textes ou à susciter des échos thématisés, et il reprend certains aspects formels du récit utopique en configurant l'espace public ainsi donné à lire. C'est cet aspect discursif que les auteurs nomment "la dimension littéraire» du Canadien et qu'ils ont étudié comme un tout cohérent. L'ouvrage est divisé en sept chapitres, 


\section{REVUE INTERNATIONALE D'ÉTUDES QUÉBÉCOISES}

signés par des auteurs différents et portant successivement sur la facture du journal, le discours scientifique, le discours sur l'étranger, les faits divers, le discours historique et social et la littérature proprement dite. Ces études monographiques sont précédées d'une réflexion générale sur l'utopie que signe Cambron. Les éditeurs ont eu l'heureuse idée de joindre à l'ouvrage un fac-similé du journal $L e$ Canadien, reproduisant la livraison du 4 janvier 1844.

La qualité d'ensemble de l'ouvrage est inégale (le dernier chapitre en particulier est nettement plus faible), ce qui paraît inévitable dans ce genre d'entreprise. On comprend que les auteurs aient voulu explorer de nouvelles voies, éviter le piège de la seule analyse de contenu, le plus souvent restreinte aux éditoriaux, qui caractérisait jusqu'à maintenant la lecture des journaux canadiens du XIXe siècle. En même temps, on reste un peu mal à l'aise du peu de cas fait des données connues qui auraient pu être intégrées, même après coup, à l'analyse. Il n'y a ainsi aucune référence à l'utopie Vattemare (dont les discussions s'étendent sur plus de deux ans et qui sert encore de référence dans le journal du 4 janvier 1844), pourtant clairement énoncée, ou à la manière dont le journal rend compte de la sphère publique elle-même (carnet mondain, convocations, procès-verbaux, comptes rendus de réunions des diverses sociétés et associations, littéraires, scientifiques, professionnelles ou politiques). De même, la vision de l'Union paraît un peu gommée, mais on comprend cependant que prime ici la lecture de cette construction dystopique qu'est en quelque sorte le dépassement des rébellions. En conséquence, et peut-être comme les Canadiens de l'époque euxmêmes, on sait où la construction du social a craqué, mais on ignore encore comment la société va se reconstruire.

En revanche, les auteurs observent une croissante uniformité dans le ton du journal durant la période étudiée. Le Canadien apparaît comme un journal romantique dont le discours construisant l'avenir s'inscrit dans un temps qui est donc aussi pré-utopique. La lecture repère la condensation graduelle de l'ethos qui allait mener, dans la seconde moitié du siècle, jusqu'aux véritables utopies qui sont énoncées dans le dernier chapitre du Charles Guérin (de Pierre-JosephOlivier Chauveau) et dans le Jean Rivard (d'Antoine Gérin-Lajoie), 


\section{RECENSIONS}

avant de culminer dans le messianisme du dernier quart de siècle. Plutôt que de chicaner sur ses carences historiennes, je crois qu'il faut d'abord saluer l'originalité d'une telle entreprise et espérer que semblable lecture soit réalisée de L'Avenir ou de La Vérité.

Lucie Robert

Université du Québec à Montréal

\section{Daniel Jacques \\ Nationalité et modernité \\ Montréal, Boréal, 1998, 268p.}

La nation, qui représente pourtant la forme d'association politique la plus répandue à notre époque, a cessé d'être un idéal politique. Cet état de choses, analysé par Daniel Jacques, n'est selon lui qu'une manifestation, parmi bien d'autres, d'un mal caractéristique de ce siècle : la confusion des allégeances. Incapables de lier de façon cohérente les obligations résultant de leur appartenance à une communauté et certaines nécessités politiques auxquelles ils font face, nos contemporains auraient choisi de faire prévaloir les secondes, sapant ainsi les assises morales de la nation et sectionnant du même coup le lien qui unit le moral et le politique. Pourtant la pluralité des allégeances, marque distinctive de la vie dans une société démocratique, ne nous condamne pas à une telle confusion car, selon l'auteur, elle trouve sa source ainsi que son principe intégrateur au sein même des idéaux de la modernité qui ont façonné l'évolution des sociétés occidentales. Loin de vouloir déplorer la pluralité des allégeances, l'auteur veut au contraire défendre la thèse selon laquelle la nation peut en constituer une synthèse cohérente et qu'elle est à cet égard, "la condition de réalisation de l'idéal moderne» (p. 19).

La question de la légitimité politique de la nation nous renvoie donc, soutient l'auteur, à l'histoire de la pensée politique et aux débats philosophiques au cours desquels se sont précisés les idéaux et les exigences, parfois conflictuels, de la modernité. Dans un premier chapitre, intitulé «L'esprit d'égalité», l'auteur soutient, en s'appuyant 